\title{
偏 次壓縮 鋼 柱新算式の提案
}

准員横尾義 貫 ${ }^{*}$

\section{丙 容 梗 摡}

現在偏心厎縮銅柱に用ひられてるる算式は中心厎縮の場合を modify せるもので、果して合理的なるのか不时である。

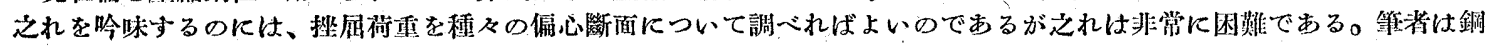

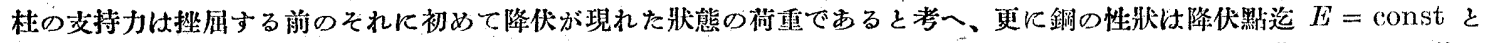

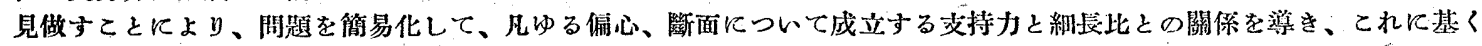
計算法を示し、現行算式を批評した。
1. 綪
2. 基本式の誘導
3. 基本支持力と妿全淬
4. 結 言

目

\section{1. 緒}

\section{$\overline{\bar{F}}$}

中心㗛繀鋼杜の挫屈については風に Euler. Engesser, Kármann，等によつて柱屈應力度と細長比との關係が解明さ れて、之れに基き、今日

$$
\omega \frac{P}{F} \leqslant \sigma_{z u l}
$$

なる式による $\omega$-涯分㳘分精確な根㨜をるつ式として用ひられ $\tau$ 居る。

其の後偏心然縮鋼杜について Ros, E. Chwalla, K. Jezek 舅によつて破究が淮められ、等大の且偏心が杜の同じ侧にある 楾な曲げモーメントを材端に受ける鋼杜については挫屈隹力度

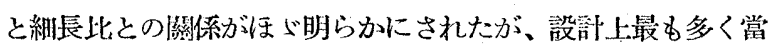
晌ずる材端に働く曲げモーメントの大きさ、向きが異る場合に つては未米坛似解法が示されてるるのみで解明されて居ら ず、設胡の訪算式として $\omega$-法を修正した

$$
\frac{\omega P}{F}+\frac{M}{W} \leqslant \sigma_{\mathrm{zul}}
$$

なる形式が不安なるまつに使用されてるる。䓝後者の㑥合は K. Ježek の示した解析的方法に做へば任意の矣面について解

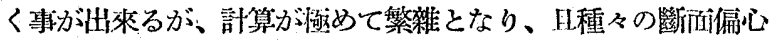

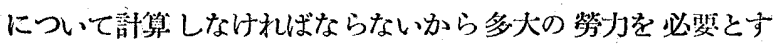
る。

此處に箠者は次の2つの假定を設ける。則ち

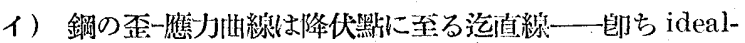
plastischーなりとする。

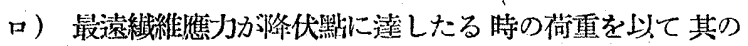
杜の支持力とする。

$$
\sigma_{s}: \text { 降伏默應打度 }
$$

猫 ideal-plastisch とは鋼の查一應力曲線力゙降伏默に至る汽

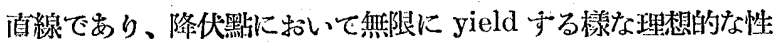

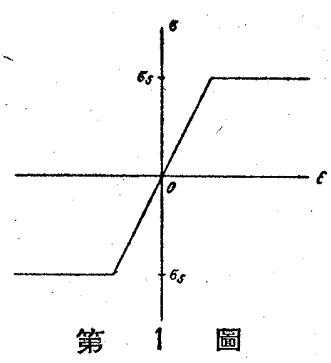
狀を指すのでせつて(第 1 㘣)、か く假定すれば中心鷹維杜にては Engesser-Kárman 的な 効果が

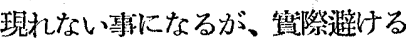
事の出來微小の偏心を考へて偏 心厚縮杜とすれば、此の効果が現 はれ䁈驗值とよく一致するる。即ち イ）の假起は管賞なりと云へる。

上記の如き イ)、口) の假定を㩖く事により、問題は $E=$ const なる場合となり、取扱ひ谷易となり、鎆杜の支持力と細

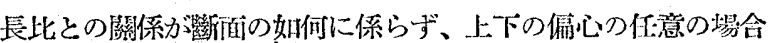
について求める事加出來ることやなる。

\section{2. 基本式の誘導}

記號を次の如くする。

$$
\begin{aligned}
& \text { l: 材長 } \\
& F \text { : 斷 面 積 } \\
& I: \text { 喵㮌2 次菜 }
\end{aligned}
$$

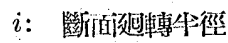

$$
\begin{aligned}
& \kappa: \text { 核心牛丝 } \\
& \lambda \text { : 細 聚 比 } \\
& P \text { : 荷 重 } \\
& \sigma_{s}: \text { 降伏㫮篧力度 } \\
& a_{1} \text { ： 材端 } A \text { の荷重の偏心 } \\
& a_{2} \text { ：材端 } B \text { の荇䨘の偏心、 }\left|a_{1}\right| \geqslant\left|a_{2}\right|, a_{1} \text { と同じ侧に } \\
& \text { 䖝る時を十とす。 } \\
& \sigma_{0}=\stackrel{P}{F} \text { 平均覧縮應力度 } \\
& m_{1}=\frac{a_{1}}{k} \\
& m_{2}=\frac{a_{2}}{k} \\
& p=\frac{m_{2}}{m_{1}}=\frac{a_{2}}{a_{1}} . \text { 從つて }-1 \leqslant p \leqslant 1
\end{aligned}
$$

* 京都帝或大學工學研觉所所負

1) M. Roš: Die Bemessung zentrisch und exzentrisch gedxückter Stäbe auf Knickung, Berichte über die II. Internationale Tagung für Brückenbau u. Hochbau, 1928, S. 283.

2) E. Chwalla: Die Theorie des aussermittig gedrückten Stabes aus Banstahl. Stahlban 1934.

3) K. Jě̌ek: Die Festigkeit von Druckstäben aus Stahl, 1937.

4) 网.: S. 218.

5) 间上: S. 237 . 


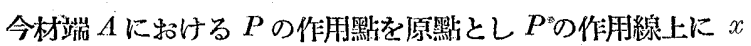
軸をとり、 $x$ 默に怙ける材の $x$ 軸小りの距離を $y$ とし、材長に

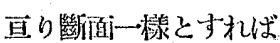

$$
y^{\prime \prime}=-\alpha^{2} y, \quad \alpha^{2}=\frac{P}{E I}
$$

となる。之れを解いて

$$
y=A \sin (\alpha x+B), \quad A, B=\text { 任意常數 }
$$

しかるに煵邊條件は $x=0 ; \quad y=a_{1}$

$$
x=l ; \quad y=a_{2}
$$

$$
\text { これより } \quad A=\frac{a_{1} \sqrt{\left(1+p^{2}\right)-2 p \cos \alpha l}}{\sin \alpha l}
$$

を得。

$$
\begin{aligned}
& p=1 \text { と抬けば, } A=\frac{a_{1}}{\cos \frac{\alpha l}{2}}, \sin \frac{\alpha l}{2} \neq 0 \\
& p=-1 \text { と怙けば } A=\frac{\alpha_{1}}{\sin \frac{\alpha l}{2}}, \quad \cos \frac{\alpha l}{2} \neq 0
\end{aligned}
$$

即ち $-1<p \leqslant 1$ に括いてては $\alpha l$ が $\pi$ に近づくに從つて $A$

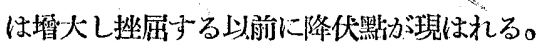
$p=-1$ に和いては $\alpha l=\pi$, 即ち Euler 式

$$
\lambda_{k}=\pi \sqrt{\frac{E}{\sigma_{0 k}}}
$$

を滿足する $\sigma_{o k}, \lambda_{k}$ にて $A$ の值不定となり、降伏䓡が現れな くとも挫厤する。

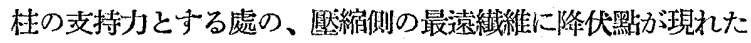
瞬間に括ける㹜態の $\sigma_{0}, \lambda$ を $\sigma_{0}, \lambda_{n}$ とし、以上此の關係を 求める。

(i) $p=1$

降伏點が現れた點に於ては

$$
\begin{array}{ll} 
& \sigma_{s}=\frac{P}{F}+\frac{P, y}{W}=\sigma_{0}\left(1+\frac{y}{k}\right) \\
\text { 故に } \quad & y=k\left(\frac{\sigma_{s}-\sigma_{0}}{\sigma_{0}}\right)
\end{array}
$$

である。

此の場合は降伏熙が現れるのは材の中央であつて、(1)'，(3) を等しと置いて

$$
\lambda_{n}=2 \sqrt{\frac{E}{\sigma_{0 n}}} \cos ^{-1} m_{1} \frac{\sigma_{0 n}}{\sigma_{s}-\sigma_{0 n}}
$$

を得。

(ii) $-1<p<1$

a. 比較的太知、杜では $y_{\max }$ が $A, B$ の外にあり、先づ杜

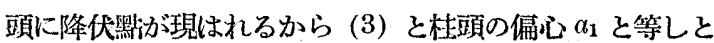
置いて

$$
\sigma_{0 n}=\frac{\sigma_{s}}{1+m_{1}}
$$

を得。

b. 比較的細長い杜では' $y$ max が $A, B$ の中間にあり、降伏

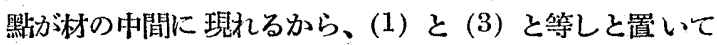

$$
\cos \alpha l=\frac{p m_{1}^{2}-\sqrt{p^{2} m_{1}^{4}-X^{2}\left[m_{1}^{2}\left(1+p^{2}\right)-X^{2}\right]}}{X^{2}}
$$

但し

$$
X=\frac{\sigma_{s}-\sigma_{0 n}}{\sigma_{0 n}}
$$

$$
\begin{aligned}
& \text { 故に } \lambda_{n}=\sqrt{\frac{E}{\sigma_{0 n}}} \\
& \cos ^{-1} \frac{p m_{1}^{2}-\sqrt{p^{2} m_{1}^{4}-X^{2}\left[m_{1}^{2}\left(1+p^{2}\right)-X^{2}\right]}}{X^{2}} \\
& \text { 但ᄂ } X=\frac{\sigma_{s}-\sigma_{0 n}}{\sigma_{0 n}}
\end{aligned}
$$

を得。

c. $a, b$ の交慗は (5) を（6）に代大して

$$
\lambda_{n}=\sqrt{\frac{E}{\sigma_{o n}}} \cos ^{-1} p
$$

(iii) $p=-1$

$y_{\max }$ は $A, B$ の上か若しくは外にあるから降伏點が現はれ るのは杜頭であるから

$$
\sigma_{0 n}=\frac{\sigma_{s}}{1+m_{1}}
$$

此の場合は此較的細長桂では降伏が表れぬ前に挫屈する事が あるから

$$
i_{k}=\pi \sqrt{\frac{E}{\sigma_{\theta k}}}
$$

と作せ考慮せねばならぬ。以上求められた (3)，(4)，(5)，(6)

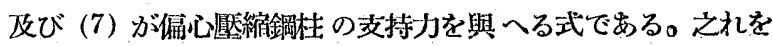
今 $\sigma_{s}=2,400 \mathrm{~kg} / \mathrm{cm}^{2}, E=2,100,000 \mathrm{~kg} / \mathrm{cm}^{2}$ とし $m=0.1$,

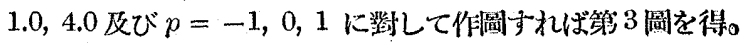

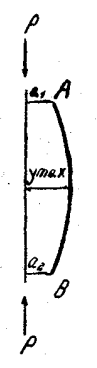

(1) $p=1$

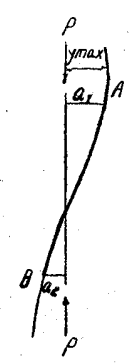

(ii) $-1<p<1$

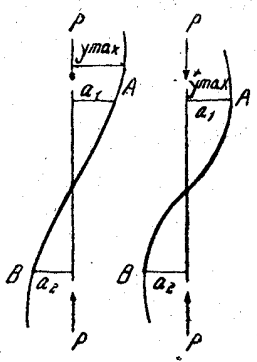

(iii) $p=-r$
第 2

圖

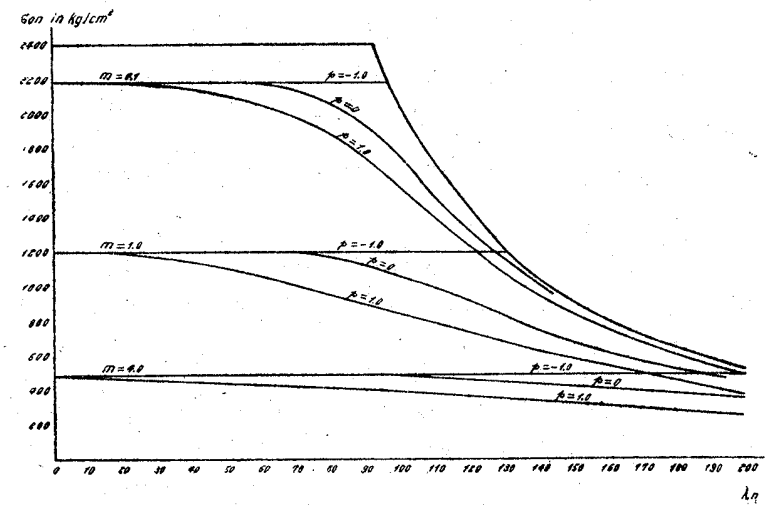

3 


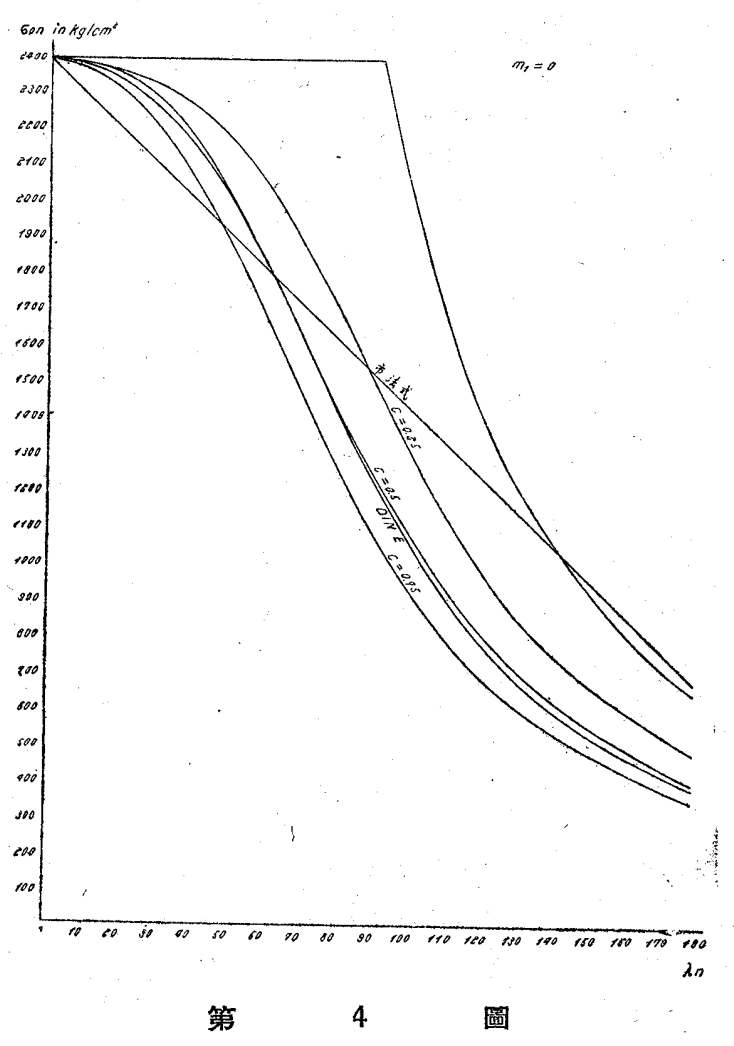

3. 基本支持力と安全率

$$
\begin{aligned}
& \text { 矩杜に呿いては、支持力は } \sigma_{0 n}=\frac{\sigma_{s} !}{1+m} \\
& \text { 訢谷支持力は }
\end{aligned}
$$$$
\text { 即ち安全到は }
$$

$$
\nu_{0}=\frac{\sigma_{0 n n}}{\sigma_{0 \mathrm{zul}}}=\frac{\sigma_{\mathrm{s}}}{\sigma_{\mathrm{zal}}}=\frac{2.4}{1.4}=1.714
$$

であるが、值に之れと同じ安全率を以て2.に求められた $\sigma_{\| n}$ を除して長杜の㒛容支持力とする事は出來ない。賽際は避くべ からざる種々の事情が加はる䉆に理諭的に求められた支持力よ りは低い支持打を持つが、之等の事情の中其の影響が入と其に

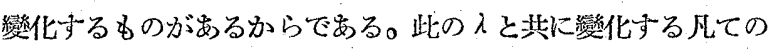

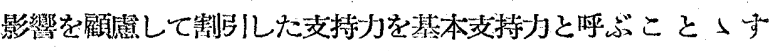
る。基本交持力に對して部容交持力は安全率 レ0を有寸る。

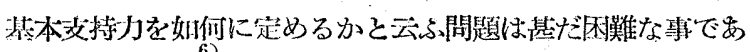
るが、DINE 4114 では中心厤綃杜について次の姐き考へによ つて站めてみる。

$\lambda$ と期變化ずる影響を持つ事情として、避くべからざる 作用默の偏倚、材の曲り、質の不均一、が考配的な者と考へ 之等の影響を

$$
\begin{aligned}
& m_{0}=c \cdot\left(\frac{\lambda}{100}\right)^{2} \\
& \text { 但し } C=0.75 \text { (st } 37 \text { に對して) } \\
& C=0.95 \text { (st } 52 \text { に對して) }
\end{aligned}
$$

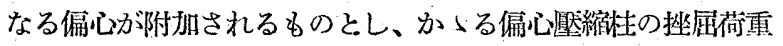
を以て基本支持力を䇥めてるる。

小論においてす此の考へに做つて、偏心 $m_{1}$ なる洔の基本支 持力は偏心

$$
m_{1}^{\prime}=m_{1}+m_{0}=m_{1}+C \cdot\left(\frac{\lambda_{n}}{100}\right)^{2}
$$

を有する支持力を以て表はす事とする。

今 $C=0.25 ; 0.50 ; 0.75$ とし $m_{1}=0$ なる特の基本支持力 曲線を描き DINE 4114 の夫れと比較すれば第 4 圖の如くな

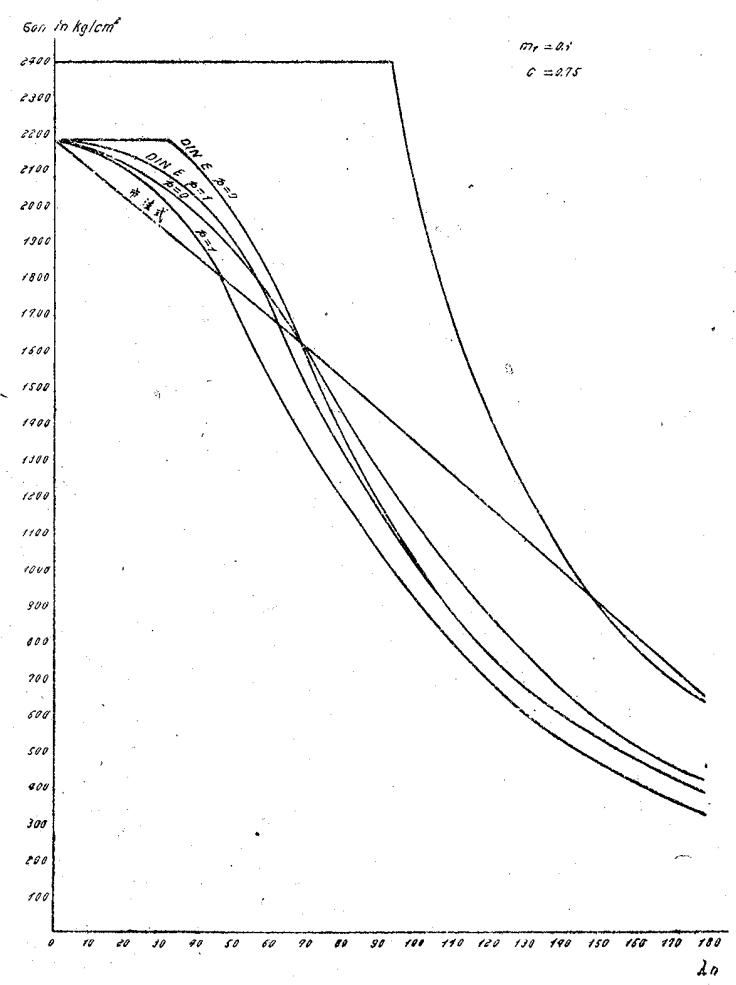
第
5
㽞

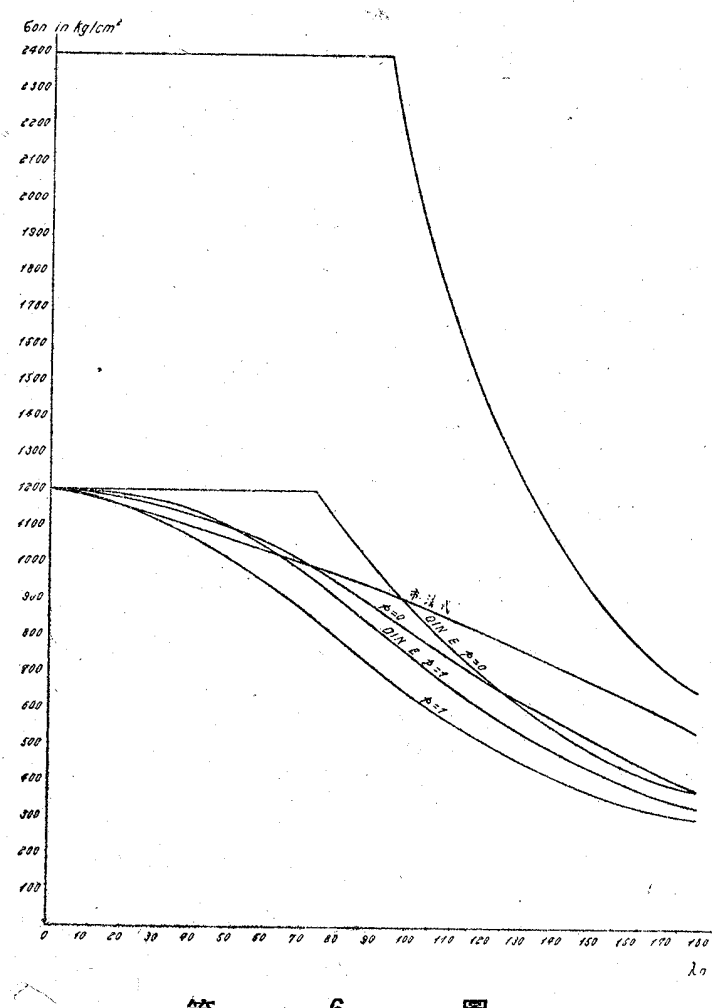

第 6 圖

6) L. Chwalla: Erlänterungen zur Begründung des Normblattentwurfes (DINE 4114), 


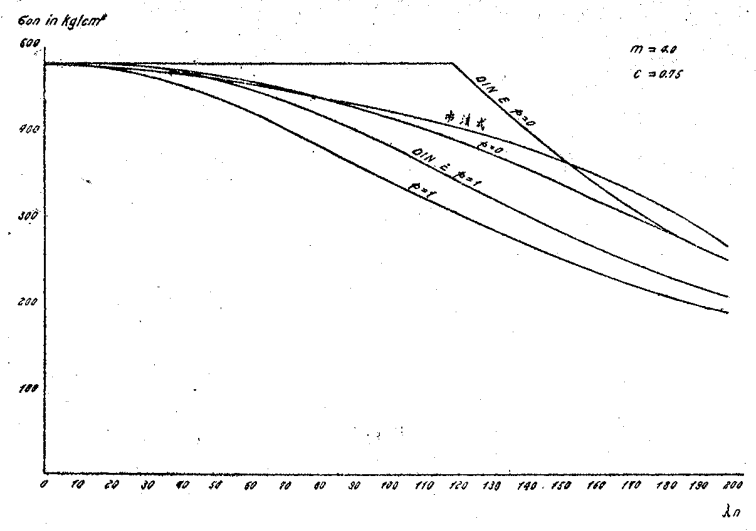

第 7 圆
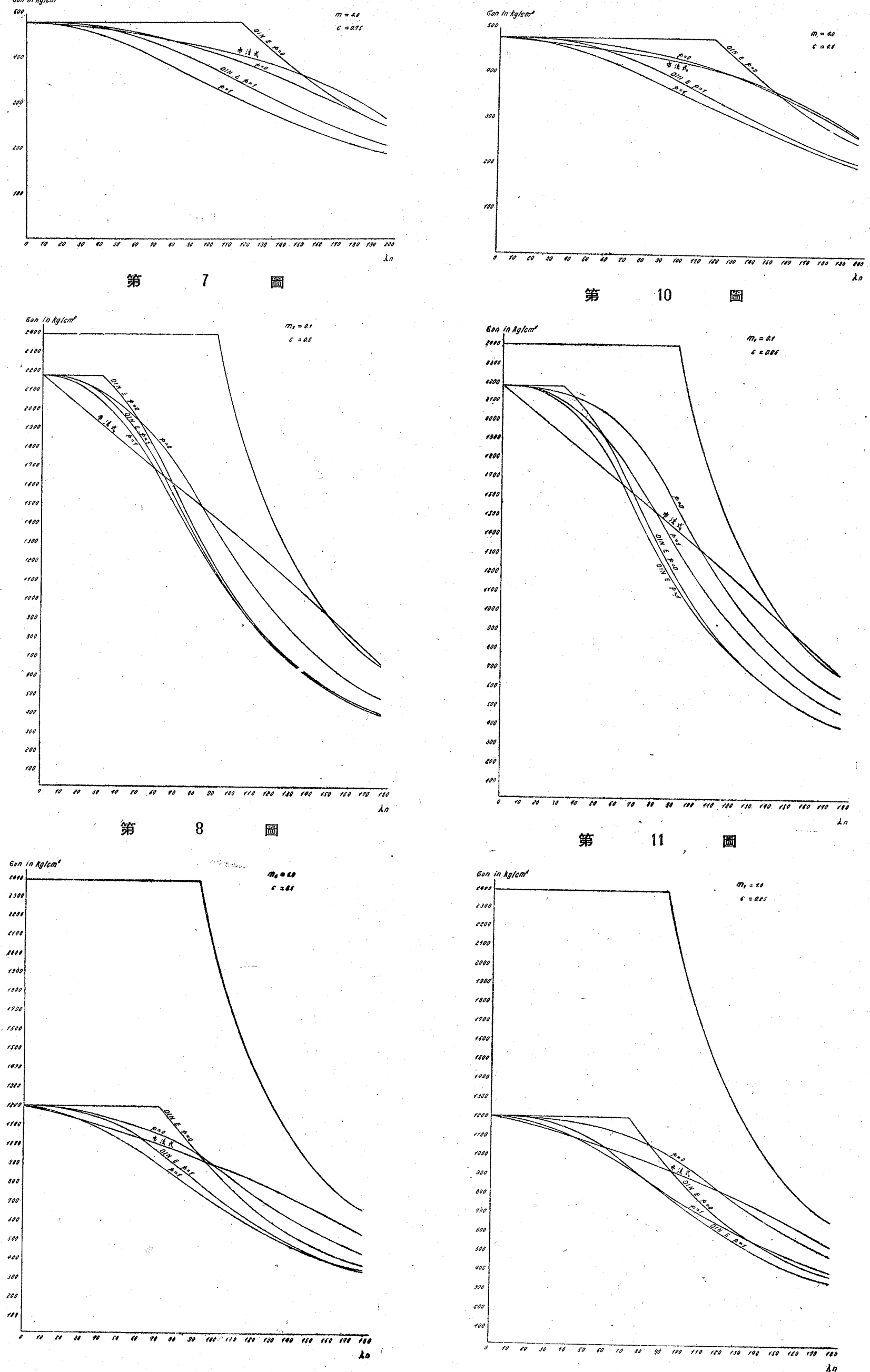

第 9 圆

第 $\quad 12$ 


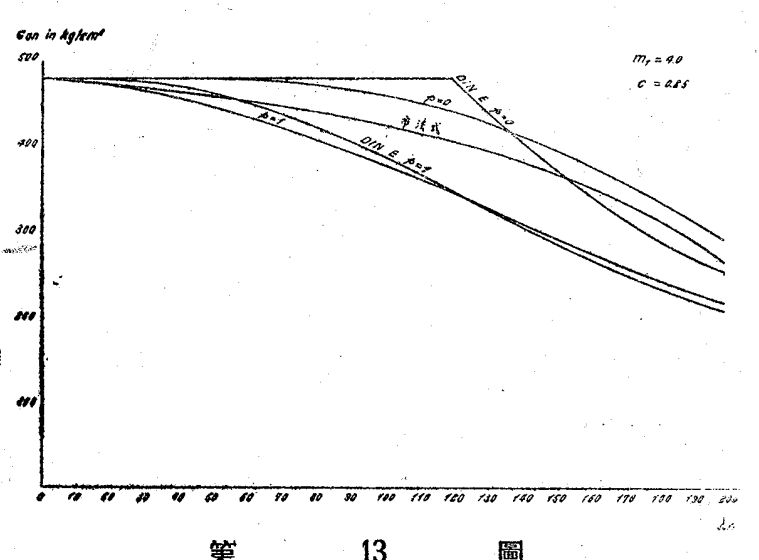

第

を作る時

$$
\sigma_{0}^{\prime} \leqslant \frac{\sigma_{s}}{1+m_{1}}
$$

なるを裂し、更に次の條件を满足すれば安全である。

$$
\lambda^{\prime}>\lambda
$$

但し $\lambda^{\prime}$ は

$$
\begin{aligned}
& \text { (i) } p=1 \quad \lambda^{\prime}=2 \sqrt{\frac{E}{\sigma_{0}^{\prime}}} \cos ^{-1} m_{1}^{\prime} \frac{\sigma_{0}^{\prime}}{\sigma_{s}-\sigma 0^{\prime}} \\
& \text { (ii) }-1<p<1 \\
& \lambda^{\prime}=\sqrt{\frac{E}{\sigma_{0}}} \cos ^{-1} \frac{p m_{1}^{\prime 2}-\sqrt{p^{2} m_{1}{ }^{4}-X^{2}\left[m_{1}{ }^{2}\left(1+p^{2}\right)-X^{2}\right]}}{X^{2}} \\
& \text { (iii) } p=-1 \quad \text { 但L } \quad X^{\prime}=\frac{\sigma_{s}-\sigma_{0}^{\prime}}{\sigma 0^{\prime}} \\
& \lambda^{\prime}=\pi \sqrt{\frac{E}{\sigma_{0}}}
\end{aligned}
$$

猶以上の如くして設請于する事は相啗煩しいから、それを簡 便に圖表なり、公式になりにまとめる事汸望しいので、これが 残されたる問題である。

次に $C=0.5$ として第 8 圖一第 10 周について DINE 4114 の設詮式を批制してみると次の事が云へる。

(i) $p=1$ なる時 DINE は本提案と比校的よく一致する。

(ii) $p=0$ なる洔 DINEによる佔、即ち緒言の（2）式に 呿い,

$$
M=P \frac{\left(\alpha_{1}+\alpha_{2}\right)}{2}
$$

と扣く方法によると太短い杜で大に過ぎ、細辰い杜で小に過ぎ 不適賞である。又 $M=P a_{1}$ とすれば $p=1$ の明線となり本 提案のより相當小さな做となり不經濟でる。 